\title{
Evaluation of Exhaled Nitric Oxide in Schoolchildren at Different Exhalation Flow Rates
}

\author{
CHRISTOPHE PEDROLETTI, WILHELM ZETTERQUIST, LENNART NORDVALL, AND \\ KJELL ALVING \\ Department of Woman and Child Health, Karolinska Institutet, S-171 76 Stockholm, Sweden [C.P.]; \\ Department of Physiology and Pharmacology, Karolinska Institutet, S-171 77 Stockholm, Sweden [W.Z., \\ K.A.]; Department of Woman and Child Health, Uppsala University, S-751 85 Uppsala Sweden [L.N.]
}

\section{ABSTRACT}

Nitric oxide (NO) in exhaled air is believed to reflect allergic inflammation in the airways. Measured levels of exhaled NO vary with the exhaled flow rate, which therefore must be standardized. The aim of this study was to estimate the optimal exhalation flow rate when measuring NO in exhaled air. We studied 15 asthmatic children (8-18 y) with elevated NO levels and 15 age-matched controls and focused on how the quality of the NO curve profile, the discriminatory power, and the reproducibility were influenced by the exhalation flow rate. We used an on-line system for NO measurements at six different exhalation flow rates in the interval of $11-382 \mathrm{~mL} / \mathrm{s}$. The fraction of exhaled nitric oxide (FENO) was highly flow-dependent as was expected. Intermediate flow rates yielded a flat and stable NO plateau and were considerably easier to interpret than those obtained at the highest and lowest flow rates. The ratio of FENO between asthmatics and controls was lower at higher flow rates and a considerable overlap in NO values was demonstrated at all flow rates except $50 \mathrm{~mL} / \mathrm{s}$. The reproducibility was much lower at more extreme flow rates and was best at $50 \mathrm{~mL} / \mathrm{s}$. We conclude that a target exhalation flow rate of approximately $50 \mathrm{~mL} / \mathrm{s}$ is to be preferred using the single-breath method for on-line NO measurements in schoolchildren. (Pediatr Res 52: 393-398, 2002)

NO, nitric oxide

\section{Abbreviations}

FENO, fraction of expired nitric oxide ppb, parts per billion

$\mathbf{C V}$, coefficient of variation
The presence of nitric oxide (NO) in exhaled air was first reported in 1991 (1) and soon after, it was discovered that asthmatics have higher levels of exhaled NO compared with controls $(2,3)$. These findings have evoked great interest because monitoring the fraction of expired NO (FENO) may be useful in the management of asthma (4), especially in children, for whom noninvasive methods are preferable (5).

It has been shown that NO is mainly synthesized in the epithelial layer in the conducting airways (6-8). This being the case, the concentration of NO in exhaled air will be highly dependent on exhalation flow rate $(9-11)$. Thus, there is a need to standardize the NO measurements, particular with respect to flow rate. However, previous (4) and current (12) recommendations on exhalation flow rate have not been based on exper-

Received February 8, 2001; accepted November 20, 2001

Correspondence: Christophe Pedroletti, Department of Allergy Q2:04, Astrid Lindgren Children's Hospital, Karolinska Hospital, SE-171 76 Stockholm, Sweden; e-mail: christophe.pedroletti@ks.se

This study was supported by the Swedish Heart Lung Foundation Samariten Foundation, Swedish Foundation for Health Care Science and Allergy Research, and the Swedish Medical Research Council (project number 10354).

DOI: 10.1203/01.PDR.0000025653.83839.77 imental data, but are compromises based on practical/technical issues.

We therefore investigated the quality of the exhaled NO curve profile, the reproducibility, and the discriminatory power of the NO values at six different exhalation flow rates in a sample of asthmatic schoolchildren with elevated levels of NO and age-matched controls.

\section{MATERIALS AND METHODS}

Subjects. Fifteen children (aged 8-18, mean 14 y), three girls and twelve boys, with asthma and elevated NO levels (>10 ppb at exhalation flow rate $150 \mathrm{~mL} / \mathrm{s}$ ) were recruited from the Allergy clinic at Astrid Lindgren Children's Hospital, Karolinska Hospital.

Thirteen of these children had atopic asthma and were sensitized to furred pets, pollen, or house dust mite. Atopy was evaluated by skin prick testing. Five subjects were steroidnaive. Mean dose of inhaled steroids was $305 \mu \mathrm{g} / \mathrm{d}$ in steroidtreated patients. A brief structured interview regarding symptoms was performed on the day of examination. Fifteen nonatopic, nonasthmatic children (aged 8-18, mean 12 y), six girls and nine boys, without history of atopy or heredity for 
atopic disease served as controls. They were selected regardless of NO levels.

Subjects were not allowed to show any sign of an upper respiratory tract infection. Pubertal girls were not examined during menstruation. All children were nonsmokers. All subjects completed the study. Medication and other subject characteristics is described in Table 1.

Nitric oxide measurements. Measurements were performed in accordance with international recommendations for on-line NO measurements previously described in the European Respiratory Society Task Force Report (4). The children exhaled at six targeted flow rates $(10,20,50,100,200$, and $500 \mathrm{~mL} / \mathrm{s})$. We used the Aerocrine NO system (Aerocrine AB, Stockholm, Sweden), including the CLD 77 AM chemiluminescence analyzer from Eco Physics AG for on-line NO measurements and monitoring of pressure. The sensitivity of the analyzer is 0.1 $\mathrm{ppb}$, the rise time $0 \%$ to $90 \%$ is $0.1 \mathrm{~s}$, the sampling flow rate $110 \mathrm{~mL} / \mathrm{s}$, and the machine lag time from the mouthpiece $0.7 \mathrm{~s}$. The children were comfortably seated, inhaled NO-free air from a reservoir and subsequently exhaled against different linear resistors (Hans Rudolph Inc, Kansas City, MO, U.S.A.). The target oral pressure at the different flow rates was 10 $\mathrm{cmH}_{2} \mathrm{O}$. As support in this maneuver the children were given a target pressure between two indicator lines at 8 and 12 $\mathrm{cmH}_{2} \mathrm{O}$. To determine NO levels at six different flow rates, resistors were changed between exhalations. We used the following resistors: $20,50,100,200,500$, and $1000(500+500)$ $\mathrm{cmH}_{2} \mathrm{O} / \mathrm{mL} / \mathrm{s}$. Three consecutive exhalations were performed at each flow rate.

Flow was calculated as the ratio between pressure and resistance and was corrected for analyzer sample flow rate. The duration of the exhalation varied with exhalation flow rate and lung capacity. All pressure and NO signals from each exhalation maneuver were stored in the computer system and redisplayed for further analyses.

NO calculations. Mean FENO was calculated during an FENO plateau of $3 \mathrm{~s}$. However, since the smaller children had limited capacity to exhale long enough at the highest flow rate, an approximated plateau of at least $1 \mathrm{~s}$ had to be accepted in these cases. A plateau was considered when FENO did not vary more than $10 \%$ or $\pm 1 \mathrm{ppb}$.

Statistical calculations. Data are expressed as geometrical mean. We used Prism $3^{\mathrm{TM}}$ software (Graph Pad Software, Inc., San Diego, CA, U.S.A.) for statistical analyses. Since NO values have been suggested to be normally distributed (13) after logarithmic transformation, differences between groups were studied by calculating the ratio of geometric means of FENO and NO output. When studying the NO scatter diagrams at each flow rate, we chose to present the discriminatory gap as the difference between the highest, separate, or mean $\mathrm{NO}$ value in the control group and the lowest value in the asthmatic group. Hence, a negative figure will represent a free interval (no overlap between groups). $t$ test was used to calculate significances. Reproducibility was examined as the coefficient of variation (CV). The time to plateau was defined as the approximate exhalation time (s) to the beginning of an acceptable NO plateau.

Ethics. The study was approved by the regional ethical committee at the Karolinska Institutet and the children and their parents gave their informed consent before inclusion.

\section{RESULTS}

Exhaled NO curve profiles. With the resistors used, the resulting calculated mean flow rates were $11,21,50,99,181$, and $382 \mathrm{~mL} / \mathrm{s}$. The mean oral pressure for all exhalations was $9.8( \pm 0.4) \mathrm{cmH}_{2} \mathrm{O}$ (corresponding oral pressure from the lowest to highest flow rate was: $10.1,9.9,10.0,9.8,9.6,9.1$ $\mathrm{cmH}_{2} \mathrm{O}$ ). The exhaled NO curve profile showed typical patterns at different flow rates.

At the highest flow rate $(382 \mathrm{~mL} / \mathrm{s})$, most children had a peak in FENO during the first third of the curve followed by a slightly down-sloping plateau (Fig. 1a). No initial NO peaks were seen at flow rates $<99 \mathrm{~mL} / \mathrm{s}$ and the $\mathrm{NO}$ curve rising time increased with decreasing flow rate (Fig. 1c). At the lowest flow rate $(11 \mathrm{~mL} / \mathrm{s})$, there seemed to be two plateaus in some cases (not shown). Even though the first plateau phase stayed within the $10 \%$ of variation definition, it slightly rose to a

Table 1. Subject characteristics of children with asthma and healthy controls

\begin{tabular}{|c|c|c|c|c|c|c|c|}
\hline \multirow[b]{2}{*}{ Age } & \multirow[b]{2}{*}{ Sex } & \multirow[b]{2}{*}{ Atopy } & \multicolumn{3}{|c|}{ Asthmatics } & \multicolumn{2}{|c|}{ Controls } \\
\hline & & & Medication & $\begin{array}{l}\text { Inhaled steroids } \\
\mu \mathrm{g} / \text { day }\end{array}$ & $\begin{array}{l}\text { Ongoing asthma } \\
\text { symptoms }\end{array}$ & Age & Sex \\
\hline 17.2 & M & yes & No medication & 0 & No & 15.9 & M \\
\hline 18.3 & M & yes & No medication & 0 & No & 10.8 & M \\
\hline 11.0 & M & yes & Budesonide & 100 & Yes & 18.7 & M \\
\hline 14.1 & M & yes & Budesonide & 100 & Yes & 16.5 & M \\
\hline 15.8 & M & yes & Fluticasone propionate & 250 & No & 10.2 & M \\
\hline 13.1 & M & yes & Budesonide & 400 & Yes & 8.1 & M \\
\hline 15.0 & M & no & Fluticasone propionate & 400 & No & 13.8 & M \\
\hline 13.3 & M & yes & Fluticasone propionate & 500 & No & 8.2 & $\mathrm{~F}$ \\
\hline 13.0 & M & yes & Fluticasone propionate (and salmeterol 100) & 500 & No & 11.0 & M \\
\hline 13.1 & $\mathrm{~F}$ & yes & Fluticasone propionate (and salmeterol 100) & 100 & No & 16.1 & M \\
\hline 11.9 & $\mathrm{~F}$ & yes & Chromoglycate & 0 & No & 13.1 & $\mathrm{~F}$ \\
\hline 17.5 & M & yes & Fluticasone propionate (and montelukast $10 \mathrm{mg}$ ) & 500 & No & 9.1 & $\mathrm{~F}$ \\
\hline 10.1 & $\mathrm{~F}$ & yes & No medication & 0 & Yes & 11.1 & $\mathrm{~F}$ \\
\hline 15.8 & M & yes & Budesonide & 200 & Yes & 10.7 & $\mathrm{~F}$ \\
\hline 8.1 & M & yes & Chromoglycate & 0 & Yes & 11.3 & $\mathrm{~F}$ \\
\hline
\end{tabular}


second breaking point leading to a flatter plateau. Furthermore, a small decline at the end of the plateau phase (lowest flow rate, $11 \mathrm{~mL} / \mathrm{s}$ ) could be observed in some individuals. Especially if the time to plateau was very long and they were running out of air (not shown). Determining the NO plateau at the highest and lowest flow rates could thus often be difficult. Intermediate flow rates $(20-100 \mathrm{~mL} / \mathrm{s})$ yielded a flat and stable NO plateau (Fig. 1b). Thus, flow rates between $20-100 \mathrm{~mL} / \mathrm{s}$ were considerably easier to interpret than those obtained at the highest and lowest flow rates. Mean time to NO plateau increased with decreasing flow rate. At the lowest exhalation flow rate $(11 \mathrm{~mL} / \mathrm{s})$, a plateau level was sometimes not reached until after $30 \mathrm{~s}$ (Fig. 1c), making the maneuver difficult for many study subjects to perform. Mean time to plateau was acceptable $(<10 \mathrm{~s})$ at flow rates $21 \mathrm{~mL} / \mathrm{s}$ and higher (Table 2).

Flow dependency of FENO and NO output. Both FENO and $\mathrm{NO}$ outputs were flow dependent in both asthmatics and controls. At all flow rates, FENO and NO outputs were significantly higher in this sample of asthmatics compared with controls. At low flow rates, small changes in flow gave rise to large changes in FENO. Thus, the upward slope of the FENO

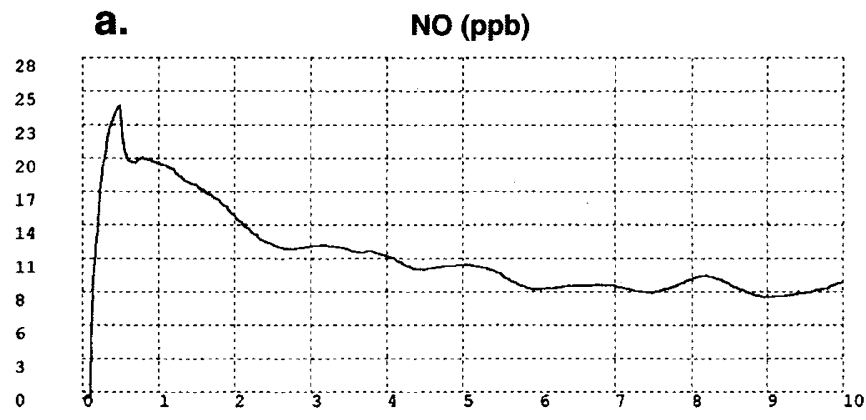

b. NO (ppb)

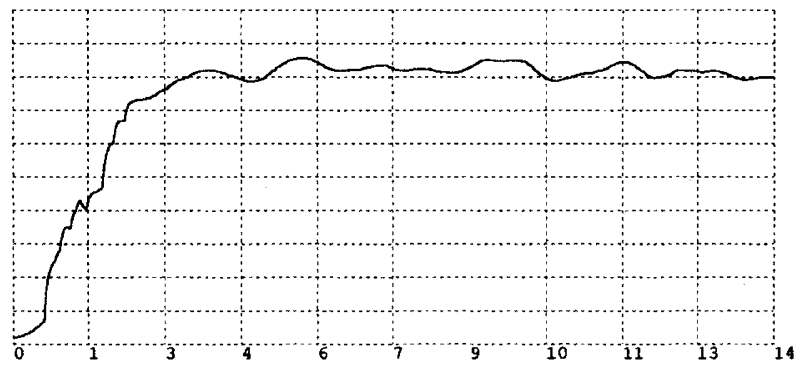

C. NO (ppb)

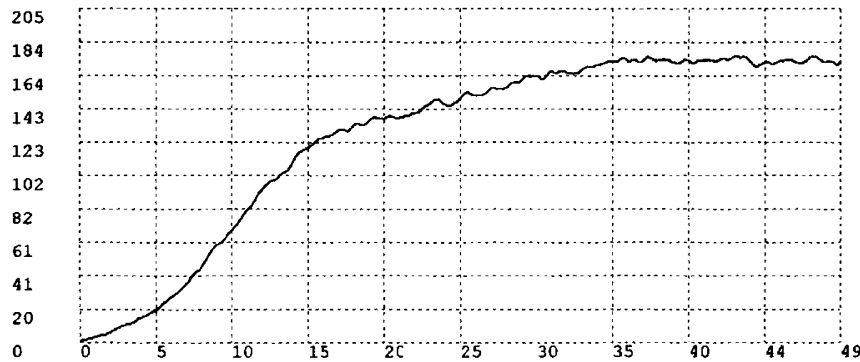

Figure 1. Typical on-line NO curve profile recordings at three different exhalation flow rates: $381(a), 50(b)$, and $11(c) \mathrm{mL} / \mathrm{s} . y$ axis FENO (ppb), $x$ axis time (s).
Table 2. Time to the start of the FENO plateau at six different flow rates

\begin{tabular}{ccccccc}
\hline Flow $(\mathrm{ml} / \mathrm{s})$ & 382 & 181 & 99 & 50 & 21 & 11 \\
\hline Time to plateau $(\mathrm{s})$ & 3.2 & 5.0 & 5.3 & 6.2 & 9.4 & 17.7 \\
\hline
\end{tabular}

versus flow curve was greatest between 11 and $21 \mathrm{~mL} / \mathrm{s}$ (Fig. $2 a$ ). In contrast, the NO output versus flow curve showed more of a biphasic pattern. The largest changes in NO output were seen at flow rates between 21 and $99 \mathrm{~mL} / \mathrm{s}$ (Fig. $2 b$ ). There was no difference between steroid-naive and steroid-treated asthmatics with regard to absolute $\mathrm{NO}$ values.

Reproducibility. The CV for FENO, NO output, and flow rate at all flow rates are presented in Table 3. The CV for FENO, NO output, and flow rate was lowest at $50 \mathrm{~mL} / \mathrm{s}$ with the exception that the $\mathrm{CV}$ for FENO in the asthmatic group alone was slightly lower at $21 \mathrm{~mL} / \mathrm{s}$. CV for flow rate was lower in the asthmatic group. We did not observe any difference between steroid-naive and steroid-treated asthmatics in the aspect of reproducibility.

Discriminatory power of FENO and NO output values at different exhalation flow rates. The means of FENO and NO

(a)

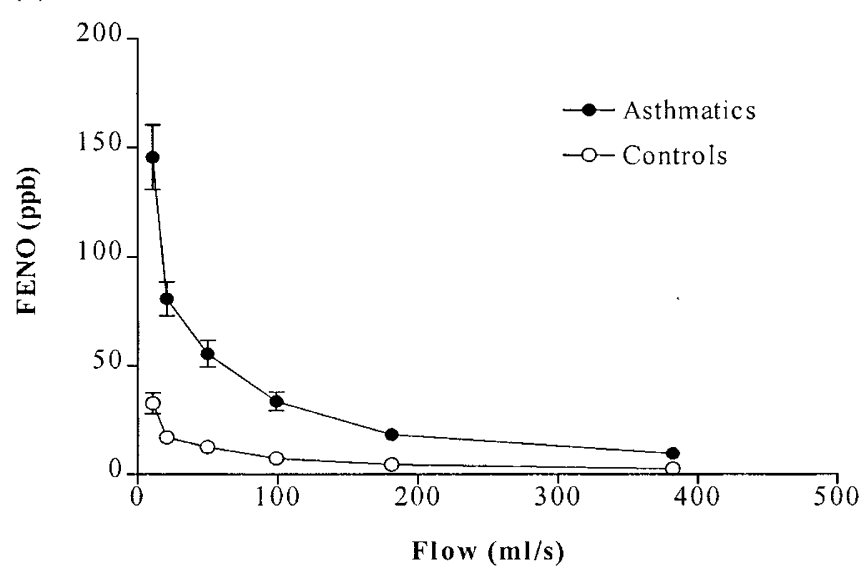

(b)

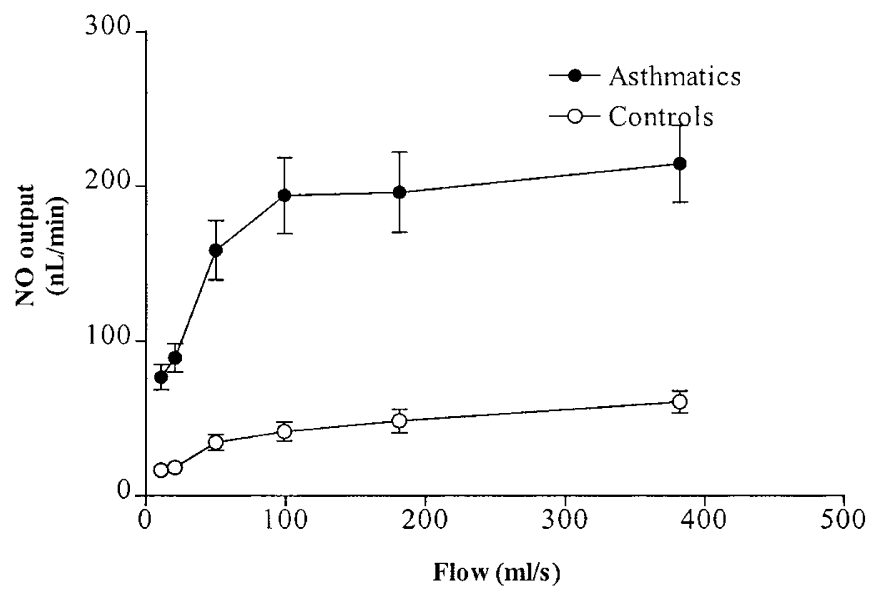

Figure 2. Exhaled FENO $(a)$ and NO output (b) (arithmetic means) at six different flow rates. The difference between groups was significant $(p<0.001)$ for both FENO and NO output at all flow rates. 
Table 3. Reproducibility, expressed as the coefficient of variation (CV) of FENO, NO output, and flow rate at six exhalation flow rates

\begin{tabular}{|c|c|c|c|c|c|c|}
\hline Flow (ml/s) & 382 & 181 & 99 & 50 & 21 & 11 \\
\hline \multicolumn{7}{|l|}{ FENO } \\
\hline CV FENO A & 7.0 & 7.3 & 7.3 & 4.6 & 4.2 & 10.9 \\
\hline CV FENO C & 21.7 & 14.4 & 14.2 & 9.6 & 13.1 & 13.7 \\
\hline \multicolumn{7}{|l|}{ NO output } \\
\hline CV NO output A & 7.4 & 6.3 & 6.8 & 3.8 & 5.3 & 12.1 \\
\hline CV NO output C & 23.2 & 15.5 & 14.9 & 9.0 & 12.5 & 14.3 \\
\hline $\mathrm{CV}$ flow rate $\mathrm{A}$ & 4.3 & 3.4 & 4.1 & 2.7 & 4.3 & 4.2 \\
\hline $\mathrm{CV}$ flow rate $\mathrm{C}$ & 8.4 & 4.3 & 5.0 & 4.1 & 4.3 & 5.6 \\
\hline $\mathrm{CV}$ flow rate $\mathrm{AC}$ & 6.3 & 3.8 & 4.6 & 3.4 & 4.3 & 4.9 \\
\hline
\end{tabular}

$\mathrm{A}=$ asthmatics, $\mathrm{C}=$ controls.

Table 4. Discriminatory power of exhaled NO (NO output, $n L / \mathrm{min})$ at six different flow rates

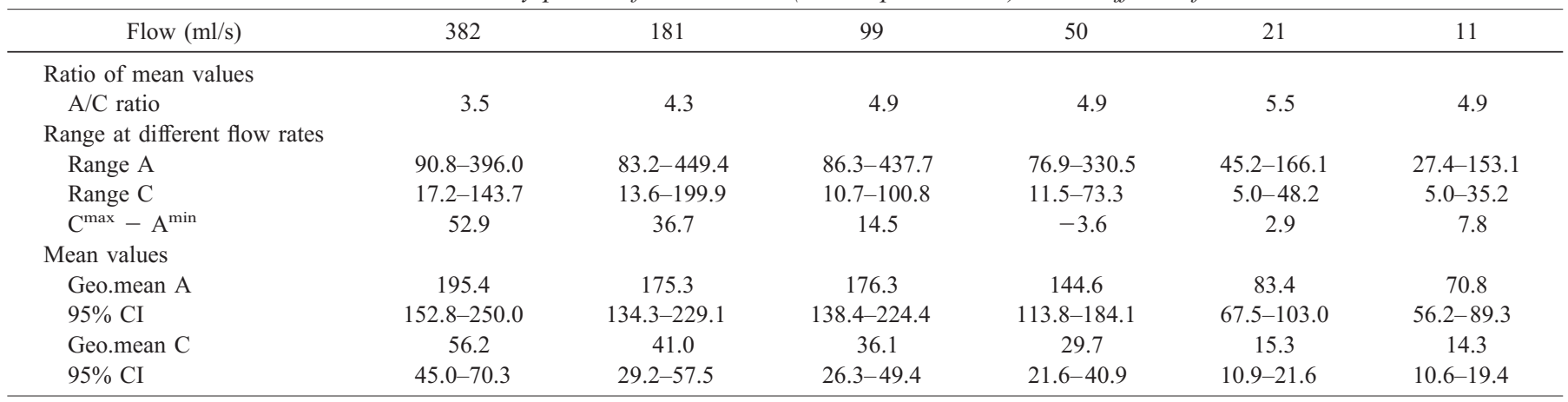

$\mathrm{A} / \mathrm{C}$ ratio $=$ the ratio between the group mean levels of NO output among asthmatics $(\mathrm{A})$ and controls $(\mathrm{C}) . \mathrm{C}^{\mathrm{max}}-\mathrm{A}^{\text {min }}=$ the interval between the lowest separate $\mathrm{NO}$ output value in the asthma group and the highest $\mathrm{NO}$ output value in the control group. Thus, a positive figure represents an overlap in exhaled NO where as a negative figure represents a free interval.

output showed no overlap between asthmatics and controls at flow rates $<99 \mathrm{~mL} / \mathrm{s}$ (Table 4). The largest gap in mean NO levels was seen at $50 \mathrm{~mL} / \mathrm{s}$. When the three separate exhalations at each flow rate were compared, only $50 \mathrm{~mL} / \mathrm{s}$ yielded results without an overlap. The $\mathrm{FENO}_{\text {asthmatics }} / \mathrm{FENO}_{\text {controls }}$ ratios were higher at lower flow rates. The largest ratio was seen at $21 \mathrm{~mL} / \mathrm{s}$.

\section{DISCUSSION}

The appropriate exhalation flow rate to be used for singlebreath on-line measurements of NO in exhaled air has been a topic of discussion the last few years. Since it was demonstrated that both FENO and NO output were highly flow dependent $(8-11,14)$, it has become important to standardize the exhalation flow rate. We studied the NO levels at six different exhalation flow rates in 15 asthmatic schoolchildren with elevated NO levels and 15 age-matched controls and found that a targeted flow rate of approximately $50 \mathrm{~mL} / \mathrm{s}$ seems to be most appropriate for single-breath on-line measurements when considering discriminatory power, reproducibility, and patient comfort. However, our intention was not to investigate the general effectiveness of NO measurements in discriminating between asthmatic and healthy children. To do so a much larger population, well characterized with regard to all clinical aspects, must be compared with adequate methodology including the use of optimal exhalation flow rate. In this methodological study, a group of asthmatic children, recruited from our clinic, primarily characterized by high NO levels, were selected to study how the difference in NO values varies with the exhalation flow rate. Our sample of asthmatic children was quite heterogeneous with regard to treatment with inhaled steroids. Some subjects were probably patients with poor compliance to treatment regimens and some subjects were maybe insufficiently treated. The controls, however, were not screened for low NO levels. They were randomly selected except for a negative history of atopy or airway disease. Nevertheless, they all showed low levels of exhaled NO. We did not find any significant difference between steroid-treated and steroid-naive patients with regard to absolute NO levels or reproducibility. If steroid-treated asthmatics would not have been included in the study, the difference in NO values between asthmatics and controls might have been even more pronounced. However, we think it is of value to incorporate both treated and nontreated asthmatics, since this is what we encounter in daily clinical practice.

Previous recommendations concerning exhalation flow rates have rather been consequences of compromises between the views of different research centers than evidence-based recommendations $(4,12)$. To our knowledge no previous study has systematically investigated exhaled NO curve profiles qualitatively at different flow rates in such a way that a suitable flow rate can be recommended.

We chose not to study NO levels at more extreme flow rates, which would not be useful in clinical practice. The NO output- 
flow curve showed almost linearity at exhalation flow rates between 99 and $382 \mathrm{~mL} / \mathrm{s}$. This observation is in good agreement with both Högman et al. (11) and Kroesbergen et al. (10) who used similar target flow rates as we did. Silkoff et al. suggested that the transfer rate of NO from the bronchial wall to the lumen is dependent on the concentration gradient between these two compartments and the diffusion capacity of NO (15). At lower exhalation flow rates $(<99 \mathrm{~mL} / \mathrm{s})$, the NO gradient becomes so small that it will limit the transfer of NO. Interestingly, we found that the loss of a linear relationship was observed at higher exhalation flow rates in asthmatics $(99 \mathrm{~mL} / \mathrm{s}$ versus $50 \mathrm{~mL} / \mathrm{s}$ for controls). The critical exhalation flow rate at which such a limitation occurs might relate to the actual production of NO. From a theoretical point of view, it could therefore be questioned whether NO should be measured at exhalation flow rates below $99 \mathrm{~mL} / \mathrm{s}$ in asthmatics. Nevertheless, the ratio in geometrical mean values between asthmatics and controls decreased at exhalation flow rates above, but not below, $99 \mathrm{~mL} / \mathrm{s}$.

Reproducibility expressed as the coefficient of variation (CV) of flow rate was better in the asthmatic children than controls, probably because they were more used to NO measurements. CV in FENO and $\mathrm{NO}$ output calculated from three consecutive exhalations was best at $50 \mathrm{~mL} / \mathrm{s}$ even though both the FENO and the NO output curve was steepest between 21-99 mL/s. There could be at least two reasons for this observation. First, the CV of the flow rate was best at a target flow rate of $50 \mathrm{~mL} / \mathrm{s}$. Since the NO levels are flow-dependent, the CV of flow will also affect the CV of FENO.

Second, the NO plateaus tended to be more stable at medium flow rates (50 and $99 \mathrm{~mL} / \mathrm{s}$ ). At higher flow rates (181 and 382 $\mathrm{mL} / \mathrm{s}$ ), a small decline during the plateau was often observed. During normal physiologic circumstances, the distal airways are known to narrow or collapse at the very last part of a forced expiration (16). This could in part cause the declining plateau seen at high flow rates, since airway narrowing will decrease the transit time resulting in reduced NO concentration, as seen during acute bronchoconstriction (17). Another explanation could be that it takes approximately $10 \mathrm{~s}$ for alveolar NO concentrations to reach steady state after inhalation $(18,19)$, and this might influence exhaled NO levels significantly at high expiration flow rates when absolute NO levels are low. The peak, always seen during the initial phase of the NO curve profile at high flow rates (181 and $382 \mathrm{~mL} / \mathrm{s})$, probably represents accumulated NO in the airways, primarily the upper airways. At the highest flow rate, the breaking point between the peak and the declining plateau often becomes diffuse and the NO plateau can be difficult to define.

Since the time to plateau was quite long at lower flow rates (11 and $21 \mathrm{~mL} / \mathrm{s})$, it became difficult for younger children to maintain concentration through the whole exhalation process and keep the flow rate fixed. Furthermore, a slight decline during the latter part of the plateau was also observed in some individuals at the lowest flow rate, probably because of collapsed bronchioles just as in higher flow rates.

Even though the NO signal could be accepted as a plateau, since it did not exceed $10 \%$ of variation, the high FENO values seen at this flow rate could vary quite a bit in real figures. The practical consequence of these findings is that the level of a plateau can be difficult to define and vary considerably at high $(>100 \mathrm{~mL} / \mathrm{s})$ and very low $(<20 \mathrm{~mL} / \mathrm{s})$ flow rates.

We also observed that the time to plateau increased with decreasing flow rate, which has already been reported in adults by Silkoff et al. (9). During the exhalation process NO-free air in the dead space is being replaced by NO-containing air from the lower airways. This takes a longer time with a lower flow rate. This confounding effect of the dead space obviously becomes a practical problem at low exhalation flow rates but can be reduced by minimizing the technical dead space. However, the NO level at the plateau phase is determined through a steady state within the airways that produce NO. This steady state depends on the transit time and, thus, on the flow rate. Therefore the time to plateau will remain a problem at very low flow rates as far as uncomfortable exhalation times is concerned.

Measuring NO should be as easy as possible both for the patient and the examiner. The goal should be to reach an NO plateau of high quality with a reasonable time of exhalation and good patient comfort. The difference between asthmatics and controls was evident and statistically significant at all flow rates under study and increased with decreasing flow rates.

In our study only $50 \mathrm{~mL} / \mathrm{s}$ yielded an overlap-free interval in NO values between the groups, when taking all separate exhalations into account. The fact that the reproducibility of the NO levels was best at this flow rate may explain this result. We conclude that a target exhalation flow rate of $50 \mathrm{~mL} / \mathrm{s}$ is preferable when considering reproducibility, discriminatory power, and patient comfort in single-breath NO measurements in schoolchildren.

\section{REFERENCES}

1. Gustafsson LE, Leone AM, Persson MG, Wiklund NP, Moncada S 1991 Endogenous nitric oxide is present in the exhaled air of rabbits, guinea pigs and humans. Biochem Biophys Res Commun 181:852-857

2. Alving K, Weitzberg E, Lundberg JM 1993 Increased amount of nitric oxide in exhaled air of asthmatics. Eur Respir J 6:1368-1370

3. Kharitonov SA, Yates D, Robbins RA, Logan-Sinclair R, Shinebourne EA, Barnes PJ 1994 Increased nitric oxide in exhaled air of asthmatic patients. Lancet 343:133-135

4. Kharitonov S, Alving K, Barnes PJ 1997 Exhaled and nasal nitric oxide measurements: Recommendations. Eur Respir J 10:1683-1693

5. Nelson BV, Sears S, Woods J, Ling CY, Hunt J, Clapper LM, Gaston B 1997 Expired nitric oxide as a marker for childhood asthma. J Pediatr 130:423-427

6. Hamid Q, Springall DR, Riveros-Moreno V, Chanez P, Howarth P, Redington A, Bousquet J, Godard P, Holgate S, Polak JM 1993 Induction of nitric oxide synthase in asthma. Lancet 342:1510-1513

7. Guo FH, Comhair SA, Zheng S, Dweik RA, Eissa NT, Thomassen MJ, Calhoun W, Erzurum SC 2000 Molecular mechanisms of increased nitric oxide (NO) in asthma: evidence for transcriptional and post-translational regulation of NO synthesis. J Immunol 164:5970-5980

8. Lundberg JO, Weitzberg E, Lundberg JM, Alving K 1996 Nitric oxide in exhaled air. Eur Respir J 9:2671-2680

9. Silkoff PE, McClean PA, Slutsky AS, Furlott HG, Hoffstein E, Wakita S, Chapman KR, Szalai JP, Zamel N 1997 Marked flow-dependence of exhaled nitric oxide using a new technique to exclude nasal nitric oxide. Am J Respir Crit Care Med 155:260267

10. Kroesbergen A, Jobsis Q, Bel EH, Hop WC, de Jongste JC 1999 Flow-dependency of exhaled nitric oxide in children with asthma and cystic fibrosis. Eur Respir J 14:871-875

11. Hogman M, Stromberg S, Schedin U, Frostell C, Hedenstierna G, Gustafsson E 1997 Nitric oxide from the human respiratory tract efficiently quantified by standardized single breath measurements. Acta Physiol Scand 159:345-346

12. Slutzky AS, Drazen JM, Silkoff PE, Gaston BM, Holden W, Romero FA, Alving K, Baraldi E, Barnes PJ, Bratton D, Chatkin JM, Cremona G, de Gouw H, Deykin A, Djupesland P, Douglas J, Erzurum S, Gustafsson LE, Haight J, Hogman M, Irvin C, Joerres R, Kissoon N, Lanz MJ, Lundberg JON, Massaro AE, Mehta S, Olin A, Permutt S, Qian W, Robbins R, Rubinstein I, Sylvester JT, Townley R, Weitzberg E, Zamel N 1999 Recommendations for standardized procedures for the online and 
offline measurement of exhaled lower respiratory nitric oxide and nasal nitric bride in adults and children - 1999. Am J Respir Crit Care Med 160:2104-2117

13. Salome CM, Roberts AM, Brown NJ, Dermand J, Marks GB, Woolcock AJ 1999 Exhaled nitric oxide measurements in a population sample of young adults. Am J Respir Crit Care Med 159:911-916

14. Beck J, Griese M, Latzin P, Reinhardt D 1999 Characteristics of flow dependency of nitric oxide in exhaled air in children with cystic fibrosis and asthma. Eur J Med Res 4:335-340

15. Silkoff PE, Sylvester JT, Zamel N, Permutt S 2000 Airway nitric oxide diffusion in asthma: Role in pulmonary function and bronchial responsiveness. Am J Respir Crit Care Med 161:1218-1228
16. Lumb AB 2000 Nunn's Applied Respiratory Physiology. 5th ed. Reed Educational and Professional Publishing Ltd, Oxford, 66-68

17. de Gouw HW, Hendriks J, Woltman AM, Twiss IM, Sterk PJ 1998 Exhaled nitric oxide (NO) is reduced shortly after bronchoconstriction to direct and indirect stimuli in asthma. Am J Respir Crit Care Med 158:315-319

18. Borland CD, Higenbottam TW 1989 A simultaneous single breath measurement of pulmonary diffusing capacity with nitric oxide and carbon monoxide. Eur Respir $\mathbf{J}$ 2:56-63

19. Pietropaoli AP, Perillo IB, Torres A, Perkins PT, Frasier LM, Utell MJ, Frampton MW, Hyde RW 1999 Simultaneous measurement of nitric oxide production by conducting and alveolar airways of humans. J Appl Physiol 87:1532-1542 